\title{
Green nano-emulsion intervention for water-soluble glyphosate isopropylamine (IPA) formulations in controlling Eleusine indica (E. indica).
}

\begin{abstract}
This article describes the development of environmentally friendly nano-emulsion system for water-soluble herbicide application. Pseudoternary phase diagrams were established in the emulsion system of fatty acid methyl esters (FAMEs)/alkylpolyglucosides (APG) and/or 3(3-hydroxypropyl)-heptamethyltrisiloxane (organosilicone)/water encompassed with $41 \%$ (w/w) glyphosate isopropylamine (IPA) as herbicide active. Pre-formulations were selected from isotropic (L) region in the phase diagrams and their emulsion system characteristics were determined. The microemulsion systems were chosen and then dispersed into water using low-energy stirring method (200 rpm for $5 \mathrm{~min})$. Oil-in-water $(\mathrm{O} / \mathrm{W})$ nano-emulsions were formed with particle sizes of diameter less than $200 \mathrm{~nm}$. The nano-emulsion systems showed significantly lower surface tension than a commercial formulation (Roundup®). In the biological application study, treatments of nano-emulsion formulations and Roundup ${ }^{\circledR}$ were applied on narrow-leaved weed Eleusine indica. Multiple doses of glyphosate IPA of the treatments were applied for the construction of dose-response curves for determination of effective dose (ED50). The nano-emulsion formulation showed lower ED50 was $0.40 \mathrm{~kg}$ a.e./ha in controlling the weed than Roundup® was $0.48 \mathrm{~kg}$ a.e./ha. This finding suggested that the possibility of using nano-emulsion system to increase penetration and uptake of glyphosate IPA.
\end{abstract}

Keyword: Nano-emulsions; Glyphosate; Alkylpolyglucosides; Fatty acid methyl esters; Eleusine indica. 